\title{
Restless legs syndrome in migraine patients at an outpatient clinic
}

\author{
(1) Ayşe Çağlar Sarılar ${ }^{1}$, (1) Büşra S. Arıca Polat ${ }^{2}$, (1) Nesrin Karahan ${ }^{3}$, (1) Muhittin Cenk Akbostancı ${ }^{4}$ \\ ${ }^{1}$ Erciyes University Faculty of Medicine, Department of Neurology, Kayseri, Turkey \\ 2 University of Health Sciences Turkey, Gülhane Training and Research Hospital, Clinic of Neurology, Ankara, Turkey \\ ${ }^{3}$ Gazi Mustafa Kemal State Hospital, Clinic of Neurology, Ankara, Turkey
}

${ }^{4}$ Ankara University Faculty of Medicine, Department of Neurology, Ankara, Turkey

Date submitted:

15.06.2021

Date accepted:

10.10.2021

Online publication date:

15.03.2022

\section{Corresponding Author:}

Büşra S. Arıca Polat, M.D., University of Health Sciences Turkey, Gülhane

Training and Research Hospital, Clinic of Neurology, Ankara, Turkey

busrarica@yahoo.com

ORCID:

orcid.org/0000-0001-7818-1209

Keywords: Migraine, restless legs syndrome, length of disease

\begin{abstract}
Aims: The prevalence of Restless legs syndrome (RLS) in migraine patients is estimated to be 8.7-39.0\%. In this study, we set out to compare the frequency of RLS in patients diagnosed with migraine with headache free participants.
\end{abstract}

Methods: We included 201 patients with migraine with or without aura and age and gendermatched 102 headache free group from outpatient setting in this cross-sectional study. None of the migraine patients were receiving prophylactic medications that could affect dopamine metabolism. Patients with comorbidities such as kidney disease, Parkinson's disease, rheumatoid arthritis, and polyneuropathy were excluded from this study. The headache free participants had no neurological or systemic disease, no addiction/and no medical treatment. The frequency and severity (with RLS Rating Scale) of RLS was examined in two groups.

Results: $40.3 \%$ ( $n=81$ ) of the migraine patients met the diagnostic criteria for RLS than the headaches-free participants $(15.7 \%, n=16)(p<0.001)$. The RLS $(+)$ and RLS $(-)$ migraine groups were similar in terms of age, gender, number of attacks per month, presence of aura, smoking, and family history for RLS. Disease duration was longer in the migraine patients with RLS and RLS severity was higher in patients with longer disease duration $(p<0.001$ and $p=0.05)$. Five of six patients with hypertension and migraine patients had RLS (vs. 76 of 195 for patients without hypertension, $p=0.04$ ). Logistic regression analysis showed a significant association only between the disease duration and the presence of RLS [Odds ratio: 13.25, (95\% confidence interval: 5.62-31.24), $\mathrm{p}=0.001]$.

Conclusions: This study found almost three times higher frequency of RLS in patients with migraine. RLS symptoms should be questioned during the management of patients with a migraine diagnosis, particularly in long-standing disease.

\section{Introduction}

Migraine is a chronic headache syndrome that lasts 4-72 hours, usually unilateral, throbbing, moderate or severe, and characterized by recurrent attacks that increases with routine physical activities associated with nausea and/or vomiting or photophobia, phonophobia (1). It is 2.5 times more likely in women than men, and its prevalence in Turkey is $16.4 \%$ (2).

Restless legs syndrome (RLS) is defined as the feeling of restlessness in the legs, rarely in the arms, or the desire to move the legs, which worsens in long-term inactivity especially at night, and improves with movement (3). In studies using different methods, the worldwide prevalence of RLS has been reported as $2.5-29 \%$ (4). In our country, this rate is between $5.52-9.7 \%$ according to the International Restless Legs Syndrome Study Group (IRLSSG) diagnostic criteria and it is seen twice as often in women (5-7). There are clinical and epidemiological studies show that there is a relationship between migraine and RLS (8). Both the frequency of RLS in patients with migraine and the frequency of migraine in patients with RLS is higher than 
in controls (9). The prevalence of RLS in migraine patients is estimated to be $8.7-39.0 \%(3,10)$. This association is thought to be related to a common pathophysiological link rather than comorbidity (11). The most common reason for this association may be dopamine and iron metabolism disorders. However, the etiopathogenesis of RLS and its relationship and/or comorbidity with migraine has not been clarified yet.

To the best of our knowledge, only one study was published on the prevalence of RLS in Turkish migraineurs, and it was reported that the frequency of RLS was higher than controls (12). The authors observed association of RLS with the age of the patient and duration of the disease. To contribute the existing literature and improve the in the field, we aimed in this study to compare the frequency of RLS in patients diagnosed with migraine and

Headache-free controls. We also explored the clinical characteristics of migraine patients with RLS.

\section{Methods}

\section{Migraine patients and headache-free participants}

This cross-sectional study included patients admitted to the neurology outpatient clinic and were diagnosed with migraine with or without aura according to The International Classification of Headache Disorders-III. The control group included age and gender-mathced headache free volunteers (1). The headache free group did not have any neurological or systemic disease, addiction or medical treatment. The study group and headachefree controls were evaluated by two neurologists and detailed neurological were examined. None of the migraine patients were receiving prophylactic medications such as serotonin reuptake inhibitors or amitriptyline that could affect dopamine metabolism. Age, gender, average number of migraine attacks per month, length of disease, the presence of aura, a type of aura, coexistening of hypertension, smoking, family history for RLS were recorded. Patients with comorbidities such as kidney disease, Parkinson's disease, rheumatoid arthritis, and polyneuropathy were excluded. Hemoglobin $(\mathrm{Hb})$ level above $13.0 \mathrm{~g} / \mathrm{dL}$ for men and $12.0 \mathrm{~g} / \mathrm{dL}$ for women, and serum ferritin level above $50 \mathrm{~mL} / \mathrm{ng}$ were taken as reference values (13).

All procedures were performed in accordance with the Declaration of Helsinki, Erciyes University Clinical Research Local Ethics Committee (decision no: 2021/147, date: 03.03.2021), and informed written consent was obtained from all participants or their legal representatives.

\section{Clinical evaluation}

RLS was diagnosed using the IRLSSG criteria in migraine patients and headache-free participants by two neurologists using face-to-face interview. The IRLSSG diagnostic criteria include five-questions based on the patient's history (5). Subjects who met all RLS diagnostic criteria were accepted as RLS (+). Then, the Turkish version of "RLS Rating Scale" was applied to the patients diagnosed with RLS (14). This scale consists of 10 questions each graded between 0 and 4 . While the first five questions are related to the severity of symptoms, and the last five questions are related to the effects of RLS on daily living activities or quality of life. The score obtained indicates the severity of the disease. The highest score in this tool is 40 , and while scores between 1 and 10 are classified as mild, between 11 and 20 moderate, between 21 and 30 severe, and between 31 and 40 very severe.

\section{Statistical Analysis}

We performed statistical analyses using the IBM Statistical Package for Social Sciences statistics 21.0 (IBM.Corp., Armonk, NY, 2012). Descriptive statistics were displayed as mean \pm standard deviation for continuous variables; and as counts and proportions for categorical data. The distribution normality of the continuous variables was calculated using the Shapiro-Wilk test. We used independent samples t-test to compare continuous variable fort he normally distributed variables and the chi-square test for categorical variables. We analysed the two groups with the Mann-Whitney $U$ test for the non-normally distributed variables. Logistic regression analysis was performed to explore the variables independently associated with the presence of RLS. P<0.05 was considered significant.

\section{Results}

The study included 201 patients [152 females (75.6\%), 49 males $(24.4 \%)$, with the mean age of 34.6 years \pm 11.6 ] diagnosed with migraine with or without aura, and 102 headache-free participants [67 females (65.7\%), 35 males) (34.3\%), mean age 31.9 years \pm 10.8 ] were included. There was no statistically significant difference between the two groups in terms of age and gender.

More patients $(40.3 \%, n=81)$ in the migraine patients met the diagnostic criteria for RLS than the headache-free group $(15.7 \%, n=16)(p<0.001)$.

The number of patients with RLS was 81 (40.3\%) and those without RLS was 120 (59.7\%). 77.8\% of RLS (+) and $74.2 \%$ of RLS (-) migraine patients were female $(p=0.559)$. The two groups were similar in terms of age, number of attacks per month, presence of aura, smoking, and family history for RLS. Length of disease was longer in the $(+)$ migraine patients with RLS than RLS (-) group (mean 14.6 \pm 9.7 years and 4.6 \pm 5.0 years respectively, $\mathrm{p}<0.001)$. Five of six patients with both hypertension and migraine patients had RLS (76 of 195 for patients without hypertension, $p=0.041$ ) (Table 1). Serum ferritin levels were below $50 \mathrm{~mL} / \mathrm{ng}$ in $74.2 \%$ of RLS (+) migraine patients and $79 \%$ of RLS (-) migraine patients and there was 
no statistically significant difference $(p=0.526)$. Serum $\mathrm{Hb}$ levels of the two groups were within normal laboratory values $(83.3 \%, 90.1 \%$ of patients, respectively, $p=0.173)$. Additionally, the migraine patients with severe/very severe RLS $(n=20)$ had a longer disease duration than the patients with mild/moderate RLS ( $n=61)(18.3 \pm 9.7$ years, $13.4 \pm 9.5$ years; $p=0.050)$.

Logistic regression analysis showed a significant association the disease duration and the presence of RLS (Odds ratio: 13.25, 95\% confidence interval: 5.62-31.24), $p=0.001$ ). Other potential covariates age, gender, aura, the frequency of attacks, length of disease, family history, hypertention, smoking status, $\mathrm{Hb}$ and ferritin level showed no significant association with the presence of RLS in migraineurs (Table 2).

\section{Discussion}

This study showed that RLS was more common in patients with migraine than headache-free volunteers $(40.3 \% / 15.7 \%)$. Moreover, RLS was more frequent in migraine patients with hypertension, the frequency and severity of RLS was related to the disease duration.

The frequency of RLS in healthy populations has been reported to be approximately $10 \%$ (15). However, studies also showed that this rate is approximately two to three times higher in patients with migraine. First, headache and RLS comorbidity was reported by Young et al. (16) with higher prevalence of RLS in 50 patients with headache. Later, in a case-controlled study matched for age and gender, among 411 migraine patients the frequency of RLS was significantly higher compared with the controls $(17.3 \% / 5.6 \%)(17)$. In a population-based study from Taiwan, 23.641 migraine patients and 94.564 people without migraine were compared, and an increased risk of RLS was found in migraineurs regardless of the comorbidities and migraine type (18). The prevalence of RLS in migraine patients was $33 \%$ in a single case-control study from Turkey (12). Our observation of $40.3 \%$ RLS among migraine patients is in agreement with that study. Also consistent with the literature, we found that the presence of RLS in migraineurs was about three times higher than in headache-free controls (17).

Several hypotheses have been proposed regarding the higher prevalence of RLS in migraineurs The most important of these is the idea that dopamine and iron regulation disorders are mechanisms that can lead to both conditions $(19,20)$. The reasons suggesting that the dopaminergic system affects the pathophysiology of both RLS and migraine are as

Table 1. Demographic and clinical characteristics of migraine patients with and without RLS

\begin{tabular}{|c|c|c|c|}
\hline & RLS (+) (n=81) & RLS (-) (n=120) & $p$ value \\
\hline Age (year), mean $\pm S D$ & $36.1 \pm 12.5$ & $33.5 \pm 10.9$ & $0.128^{*}$ \\
\hline Female, n (\%) & $63(77.8)$ & $89(74.2)$ & $0.559^{* *}$ \\
\hline Length of disease (year), mean $\pm S D$ & $14.6 \pm 9.7$ & $4.6 \pm 5.0$ & $0.001^{*}$ \\
\hline Presence of aura, $\mathrm{n}(\%)$ & $9(11.1)$ & $14(11.7)$ & $0.903^{* *}$ \\
\hline Smoking, $\mathrm{n}(\%)$ & $26(32.1)$ & $28(23.3)$ & $0.281^{* *}$ \\
\hline Hypertension, n (\%) & $5(6.2)$ & $1(0.8)$ & $0.040^{* *}$ \\
\hline Frequency of attacks & & & $0.442^{* *}$ \\
\hline Episodic, n (\%) & $76(93.8)$ & $109(90.8)$ & - \\
\hline Chronic, n (\%) & $5(6.2)$ & $11(9.2)$ & - \\
\hline
\end{tabular}

Table 2. Regression coefficients of logistic regression of migraine patients with RLS

\begin{tabular}{llll} 
& OR & $\mathbf{9 5 \%} \mathbf{C l}$ & p value \\
\hline Age & 1.02 & $0.99-1.04$ & 0.11 \\
\hline Gender & 0.89 & $0.38-2.06$ & 0.79 \\
\hline Presence of aura & 0.74 & $0.28-1.95$ & 0.55 \\
\hline Length of disease & 6.19 & $3.40-11.26$ & 0.000 \\
\hline Headache frequency & 0.75 & $0.42-1.32$ & 0.32 \\
\hline Family history & 1.75 & $0.46-6.58$ & 0.40 \\
\hline Hypertension & 7.89 & $0.89-68.31$ & 0.06 \\
\hline Hb level & 1.99 & $0.78-5.03$ & 0.51 \\
\hline Ferritin level & 0.70 & $0.30-1.58$ & 0.39 \\
\hline Smoking status & 1.51 & $0.77-2.98$ & 0.22 \\
\hline OR: Odds ratio, Cl: Confidence interval, RLS: Restless legs syndrome, Hb: Hemoglobin & & \\
\hline
\end{tabular}


follows: Dopamine-mediated symptoms (like yawning and gastrointestinal symptoms) before migraine attacks, dopamine agonists increase migraine symptoms, animal studies showed that dopaminergic pathways are involved in both RLS and migraine, and dopamine agonists are effective for treating RLS (21-23).

Concerning the iron metabolism hypothesis; it has been reported that iron deposits are observed in the deep brain nuclei in patients with migraine and that recurrent migraine attacks are related to these iron stores (24). Iron deficiency affects RLS etiology (25). Based on this information, it is thought that iron storage and therefore usable iron deficiency may be one of the common pathophysiological mechanisms of these two diseases. Besides, since iron is the cofactor of tyrosine hydroxylase, a enzyme required in the synthesis of dopamine, it may be that striatal dopamine neurotransmission is impaired in brain iron metabolism disorders and this situation leads to RLS (26). Unlike previous studies that indicated a common mechanism regarding iron metabolism, serum $\mathrm{Hb}$ and ferritin levels were similar in migraine patients with and without RLS in our study.

Various studies have reported the presence of RLS in migraine sufferers was related to the characteristics of the patient and disease (11). Age, family history for RLS, length of disease, comorbidities, frequency, and severity of headache can predict RLS occurrence $(17,18,27,28)$.

It has been concluded in some studies that migraineurs with a longer disease duration are more likely to have $\operatorname{RLS}(12,18,27)$. Similar to the previous studies, long migraine duration was associated with increased frequency of RLS in our study, some authors consider that this association occurs due to central sensitization. In central sensitization, due to the plasticity of the somatosensory nervous system in response to chronic pain, the activity of neurons and nociceptive pathways increases and this causes pain, allodynia or hypersensitivity (29). This may also be one reason why the severity of RLS, which is another significant finding, increases as the duration of the disease increases (30).

Hypertension was significantly higher in migraine patients with RLS in our study. Previous studies also showed that hypertension is more common in patients with RLS (31). It was suggested that the presence of periodic leg movements during polysomnography increases blood pressure transiently (32). Additionally, in a study-separated patients as primary and secondary RLS, patients with primary RLS were younger and the prevalence of hypertension did not increase, whereas the rate of hypertension diagnosis was more common in patients with secondary RLS (33).

This study has some limitations. Since it was conducted a cross-sectional study the temporal relationship between the diagnosis of migraine and the presence of RLS symptoms could not be evaluated. Whether the symptoms are improved after migraine treatment was also not evaluated. The number of participants in both the patient and headache-free groups were also low.

\section{Conclusion}

In conclusion, we observed a higher frequency of RLS in patients with migraine than controls. We also observed a positive association between the frequency and severity of RLS and the duration of migraine. Since both diseases negatively affect the quality of life, RLS symptoms should be screened especially when migraine is diagnosed.

\section{Ethics}

Ethics Committee Approval: The study were approved by the Erciyes University Clinical Research Local Ethics Committee (decision no: 2021/147, date: 03.03.2021).

Informed Consent: Consent form was filled out by all participants.

Peer-review: Externally and internally peer-reviewed.

\section{Authorship Contributions}

Surgical and Medical Practices: A.Ç.S., B.S.A.P., N.K., Concept: M.C.A., Design: B.S.A.P., M.C.A., Data Collection or Processing: A.Ç.S., B.S.A.P., N.K., Analysis or Interpretation: A.Ç.S., B.S.A.P., M.C.A., Literature Search: A.Ç.S., B.S.A.P., N.K., Writing: A.Ç.S., B.S.A.P., M.C.A.

Conflict of Interest: No conflict of interest was declared by the authors.

Financial Disclosure: The authors declared that this study received no financial support.

\section{References}

1. Headache Classification Committee of the International Headache Society (IHS). The International Classification of Headache Disorders, 3rd edition (beta version). Cephalalgia. 2013;33:629-808.

2. Ertas M, Baykan B, Orhan EK, et al. One-year prevalence and the impact of migraine and tension-type headache in Turkey: a nationwide home-based study in adults. J Headache Pain. 2012;13:147-157.

3. Earley CJ, Silber MH. Restless legs syndrome: understanding its consequences and the need for better treatment. Sleep Med. 2010;11:807-815.

4. Rothdach A, Trenkwalder C, Haberstock J, Keil U, Berger K. Prevalence and risk factors of RLS in an elderly population: the MEMO study. Neurology. 2000;54:1064-1068.

5. Allen RP, Picchietti DL, Garcia-Borreguero D, et al. Restless legs syndrome/Willis-Ekbom disease diagnostic criteria: updated International Restless Legs Syndrome Study Group (IRLSSG) consensus criteria--history, rationale, description, and significance. Sleep Med. 2014;15:860-873.

6. Erer S, Karli N, Zarifoglu M, Ozcakir A, Yildiz D. The prevalence and clinical features of restless legs syndrome: a door to door 
population study in Orhangazi, Bursa in Turkey. Neurology India. 2009;57:729-733.

7. Yilmaz NH, Akbostanci MC, Oto A, Aykac O. Prevalence of restless legs syndrome in Ankara, Turkey: an analysis of diagnostic criteria and awareness. Acta Neurol Belg. 2013;113:247-251.

8. Yang X, Liu B, Yang B, et al. Prevalence of restless legs syndrome in individuals with migraine: a systematic review and meta-analysis of observational studies. Neurol Sci. 2018;39:1927-1934.

9. Fernández-Matarrubia M, Cuadrado ML, Sánchez-Barros $\mathrm{CM}$, et al. Prevalence of migraine in patients with restless legs syndrome: a case-control study. Headache. 2014;54:13371346.

10. Schürks $M$, Winter $A$, Berger $K$, Kurth $T$. Migraine and restless legs syndrome: a systematic review. Cephalalgia. 2014:34:777-794.

11. Cannon PR, Larner AJ. Migraine and restless legs syndrome: is there an association? J Headache Pain. 2011;12:405-409.

12. Akdag Uzun Z, Kurt S, Karaer Unaldi H. The relationship with restless legs syndrome, fibromyalgia, and depressive symptoms in migraine patients. Neurol Sci. 2018;39:14091414.

13. Aul EA, Davis BJ, Rodnitzky RL. The importance of formal serum iron studies in the assessment of restless legs syndrome. Neurology. 1998;51:912.

14. Ay E, Helvacı Yılmaz N, Arıcı Düz Ö, Özer FF. Validity and Reliability of the Turkish Version of The International Restless Legs Syndrome Study Group Rating Scale. Acta Medica Alanya. 2019;3:105-110.

15. Hening W, Walters AS, Allen RP, Montplaisir J, Myers A, FeriniStrambi L. Impact, diagnosis and treatment of restless legs syndrome (RLS) in a primary care population: the REST (RLS epidemiology, symptoms, and treatment) primary care study. Sleep Med. 2004;5:237-246.

16. Young WB, Piovesan EJ, Biglan KM. Restless legs syndrome and drug-induced akathisia in headache patients. CNS Spectr. 2003;8:450-456.

17. Rhode AM, Hösing VG, Happe S, Biehl K, Young P, Evers S. Comorbidity of migraine and restless legs syndrome--a casecontrol study. Cephalalgia. 2007;27:1255-1260.

18. Yang FC, Lin TY, Chen HJ, et al. Increased risk of restless legs syndrome in patients with migraine: a nationwide populationbased cohort study. Medicine (Baltimore). 2016;95:e2646.

19. Allen R. Dopamine and iron in the pathophysiology of restless legs syndrome (RLS). Sleep Med. 2004;5:385-391.
20. Charbit AR, Akerman S, Goadsby PJ. Dopamine: what's new in migraine? Curr Opin Neurol. 2010;23:275-281.

21. Silberstein SD, Young WB, Mendizabal JE, Rothrock JF, Alam AS. Acute migraine treatment with droperidol: a randomized, double-blind, placebo-controlled trial. Neurology. 2003;60:315321.

22. Paulus W, Dowling P, Rijsman R, Stiasny-Kolster K, Trenkwalder C, de Weerd A. Pathophysiological concepts of restless legs syndrome. Mov Disord. 2007;22:1451-1456.

23. Connor JR, Wang XS, Allen RP, et al. Altered dopaminergic profile in the putamen and substantia nigra in restless leg syndrome. Brain. 2009;132:2403-2412.

24. Kruit MC, Launer LJ, Overbosch J, van Buchem MA, Ferrari MD. Iron accumulation in deep brain nuclei in migraine: a population-based magnetic resonance imaging study. Cephalalgia. 2009;29:351-359.

25. Connor JR, Ponnuru P, Wang XS, Patton SM, Allen RP, Earley CJ. Profile of altered brain iron acquisition in restless legs syndrome. Brain. 2011;134:959-968.

26. Earley CJ, Connor J, Garcia-Borreguero D, et al. Altered brain iron homeostasis and dopaminergic function in restless legs syndrome (Willis-Ekbom Disease). Sleep Med. 2014;15:12881301.

27. Hsu YW, Liang CS, Lee JT, et al. Associations between migraine occurrence and the effect of aura, age at onset, family history, and sex: A cross-sectional study. PloS One. 2020;15:e0228284.

28. Lucchesi C, Bonanni E, Maestri M, Siciliano G, Murri L, Gori $\mathrm{S}$. Evidence of increased restless legs syndrome occurrence in chronic and highly disabling migraine. Funct Neurol. 2012;27:91-94.

29. Pusch D. Central Sensitization: A Generator of Pain Hypersensitivity by Central Neural Plasticity. J Mol Pathophysiol. 2021;10:1.

30. Suzuki K, Suzuki S, Haruyama Y, et al. Central sensitization in migraine is related to restless legs syndrome. J Neurol. 2021;268:1395-1401. doi: 10.1007/s00415-020-10295-7.

31. Sabic A, Sinanovic O, Sabic D, Galic G. Restless legs syndrome in patients with hypertension and diabetes mellitus. Medical Archives. 2016;70:116.

32. Pennestri M-H, Montplaisir J, Fradette L, Lavigne G, Colombo $R$, Lanfranchi PA. Blood pressure changes associated with periodic leg movements during sleep in healthy subjects. Sleep medicine. 2013;14:555-561.

33. Trenkwalder C, Allen R, Högl B, Paulus W, Winkelmann J. Restless legs syndrome associated with major diseases A systematic review and new concept. Neurology. 2016;86:1336-1343. Available from: https://n.neurology.org/ content/86/14/1336 